\title{
KAJIAN INDEKS STABILITAS ATMOSTER TERHADAP KEJADIAN HUJAN LEBAT DI WILAYAH BOGOR
}

\author{
Lu'lu Muthmainati Fu'adah, Agustina Dwi Putri Ariyanto ${ }^{2}$, Hilmi Hasani Samsuri', \\ Imma Redha Nugraheni ${ }^{4}$
}

\author{
1,2,3,4 Program Studi Meteorologi, Sekolah Tinggi Meteorologi Klimatologi dan Geofisika, \\ J1. Perhubungan I No.5 Tangerang Selatan \\ Email : lulumuthma55@gmail.com
}

\begin{abstract}
Heavy rain is the weather phenomena that could pose a risk to human life such as floods. Heavy rains caused by atmospheric instability. To find stable or unstable in the atmospheric condition can use the air stability index analysis. Analyzing the stability index of air can help predict the chances of a heavy rain. In case of occurrence of heavy rain in the area of Bogor on 9,10 and 11 November 2018, viewed of index SI, LI, SWEAT, CAPE on the hour 00 UTC and 12 UTC. The expected conclusion is that there is a relation between rainfall data and stability index. Himawari-8 satellite image from monitoring at the time of the scene showed a thick cloud cover in the area of Bogor during rain events.
\end{abstract}

Keywords: Heavy rain, Stability Air, Air Stability Index, satellite

\begin{abstract}
ABSTRAK - Hujan lebat merupakan fenomena cuaca yang dapat menimbulkan resiko bagi kehidupan manusia seperti banjir. Hujan lebat disebabkan oleh ketidakstabilan atmosfer. Untuk mengetahui stabil atau labilnya kondisi atmosfer dapat menggunakan cara analisis indeks stabilitas udara. Menganalisis indeks stabiltas udara dapat membantu dalam memprediksi peluang terjadinya hujan lebat. Dalam kasus kejadian hujan lebat di wilayah Bogor pada tanggal 9, 10, dan 11 bulan November 2018, dilihat dari indeks SI, LI, SWEAT, CAPE pada jam 00 UTC dan 12 UTC. Kesimpulan yg diharapkan adalah terdapat hubungan antara data hujan dan indeks stabilitas. Dari pantauan citra satelit Himawari-8 pada saat kejadian menunjukkan tutupan awan tebal di wilayah Bogor pada waktu kejadian hujan.
\end{abstract}

Kata kunci: Hujan lebat, Stabilitas udara, Indeks stabilitas udara, Satelit

\section{PENDAhUluan}

Indonesia merupakan negara kepulauan yang memiliki dua musim, yaitu musim penghujan dan musim kemarau. Masa transisi antara dua musim tersebut adalah masa peralihan. Dimana ketika masa peralihan sering terjadi cuaca ekstrim, seperti hujan petir, banjir, tanah longsor, dan lainnya. Cuaca ekstrim tersebut sering dikaitkan dengan fenomena hujan lebat yang disebabkan oleh awan-awan konvektif. Awan-awan konvektif pada lapisan troposfer dapat mengeluarkan panas laten yang menyebabkan gangguan terhadap atmosfer sekelilingnya (Nuryanto, 2011). Tingginya pemanasan dan tersedianya banyak uap air secara fisis merupakan lahan yang subur untuk pertumbuhan awan-awan konvektif (Nurlatifah, 2012).

Analisis kondisi atmosfer pada saat kejadian hujan lebat membantu prakirawan cuaca dan ilmuwan dalam menentukan kondisi atmosfir yang mendukung kejadian tersebut (Nurrohman, 2016). Perhitungan indeks stabilitas dengan menggunakan beberapa parameter termodinamika berguna untuk memprakirakan stabilitas atmosfer (Peppler, 1988). Di Indonesia, penelitian tentang stabilitas atmosfer baik itu pencarian atau penentuan ambang batas indeks stabilitas atmosfer pada fenomena cuaca yang disebabkan oleh awan konvektif juga telah banyak dilakukan seperti Budiarti dkk., (2012) dan Manurung (2012). 
Banjir merupakan fenomena cuaca yang kerap terjadi di Indonesia, terutama di wilayah Bogor. Banjir biasanya terjadi disertai hujan deras selama berjam-jam. Dalam suatu surat kabar, diberitakan bahwa telah terjadi banjir di 2 kampung di daerah Bogor. Hal ini mendorong penulis untuk menganalisis kasus tersebut untuk mengetahui kondisi labilitas atmosfir di daerah kejadian dari segi meteorologi.

\section{METODE PENELITIAN}

\subsection{Data dan Lokasi Penelitian}

Penelitian ini mengambil lokasi penelitian di wilayah Bogor dengan koordinat .... Penelitian ini juga dilengkapi dengan dua titik kejadian banjir yang berlokasi di Kampung Lebak Soto, Kelurahan Empang, Kecamatan Bogor Selatan dan Kampung Padasuka, Kelurahan Gudang, Kecamatan Bogor Tengah, Kota Bogor. Sedangkan periode penelitian ini selama 3 hari, yaitu tanggal 9-11 November 2018.

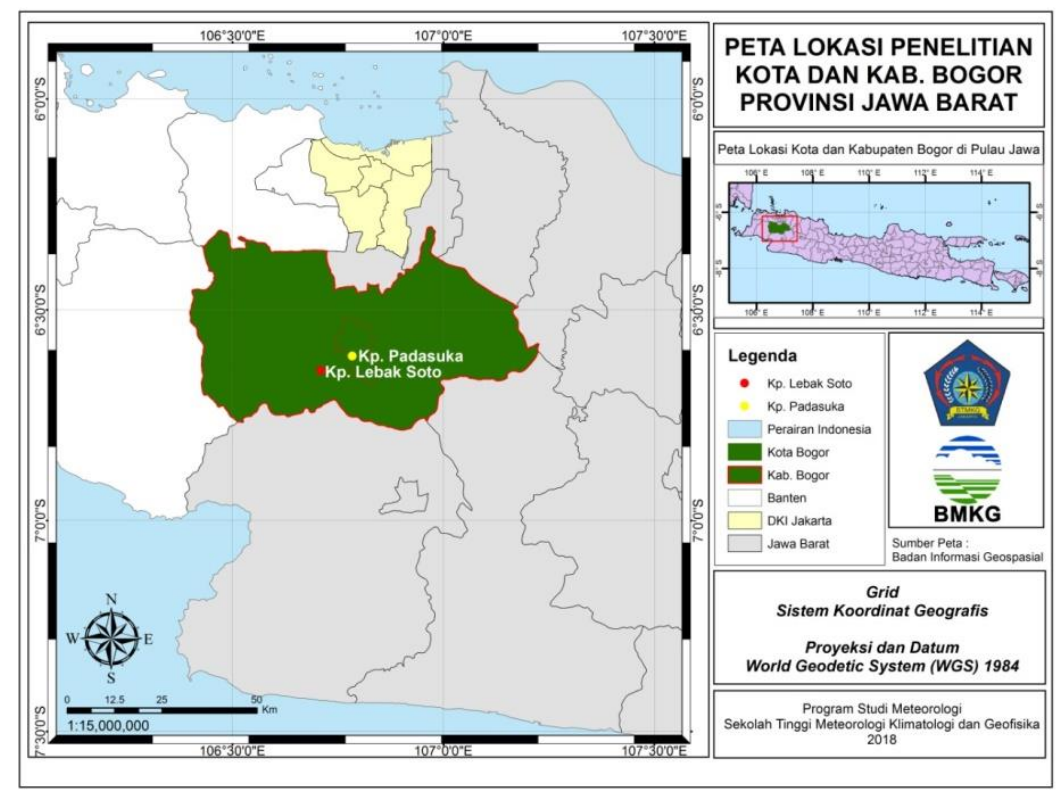

Gambar 2.1 Peta Lokasi Penelitian Kota dan Kabupaten Bogor, Jawa Barat.

Dalam penelitian ini menggunakan data berikut :

1. Data citra satelit Himawari-8 jam $00-24$ UTC tanggal 9 - 11 November 2018 kemudian diolah menggunakan aplikasi SATAID.

2. Data Curah Hujan Stasiun Meteorologi Citeko, Bogor yang diperoleh dari web ogimet.com yang kemudian diolah menggunakan aplikasi Microsoft Excel.

\subsection{Teknik Pengolahan dan Analisis Data}

Data citra satelit Himawari dengan format .Z diolah hingga mendapatkan data stabilitas atmosfer yang meliputi: SSI, LI, SWEAT, CAPE dan KI. Selain itu, data citra satelit diolah menggunakan aplikasi SATAID untuk mengetahui tutupan awan pada daerah kejadian banjir.

Data curah hujan menggunakan data synoptik dari Stasiun Meteorologi Citeko, Bogor yang digunakan untuk memverifikasi kejadian hujan lebat di wilayah Bogor. 


\subsection{Diagram Alir Kerangka Kerja}

Langkah kerja pada penelitian ini secara singkat digambarkan pada diagram alir berikut ini:

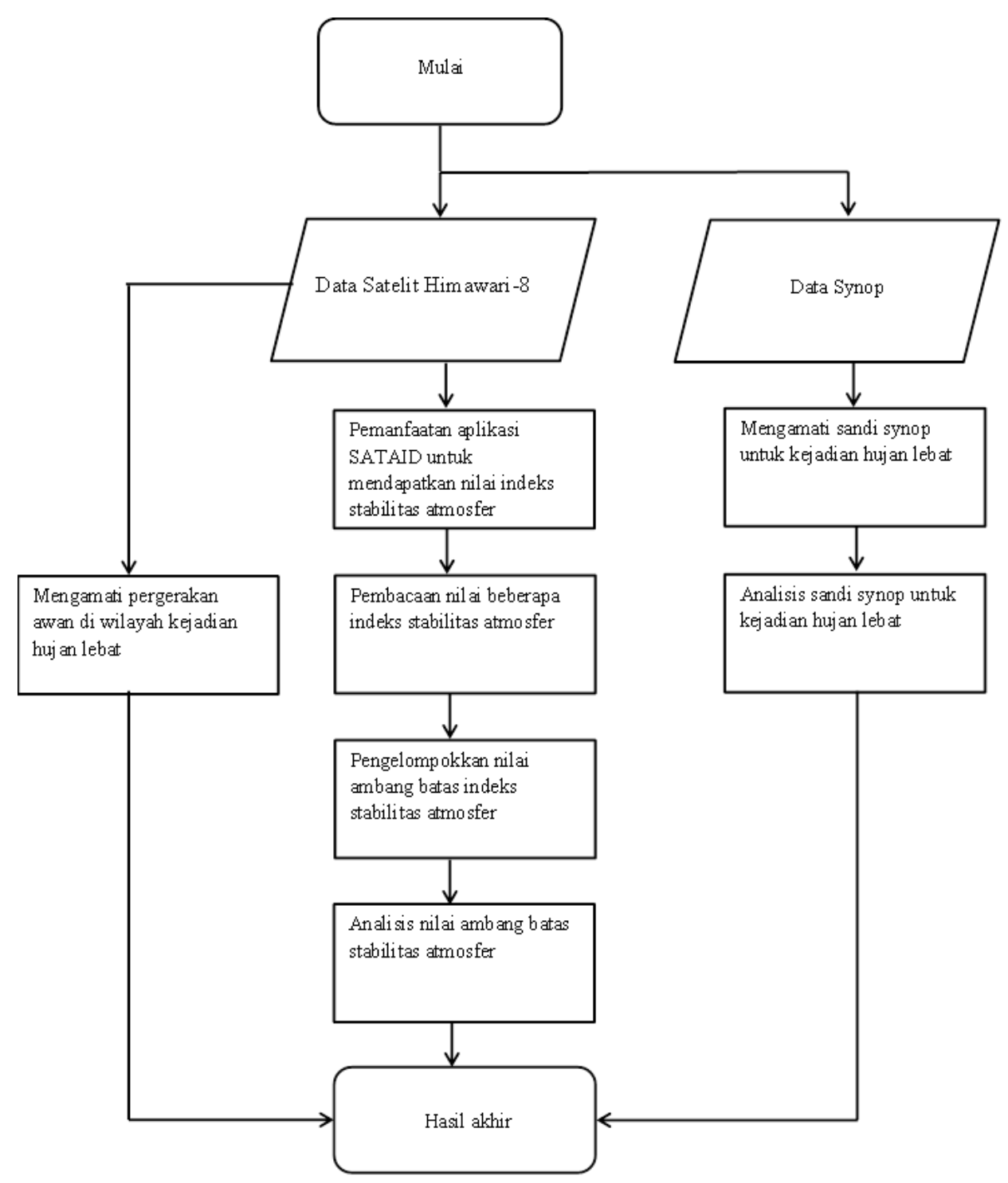

Gambar 2.2 Diagram alir langkah kerja. 


\section{HASIL DAN PEMBAHASAN}

\subsection{Intensitas Curah Hujan pada Kejadian Hujan Lebat}

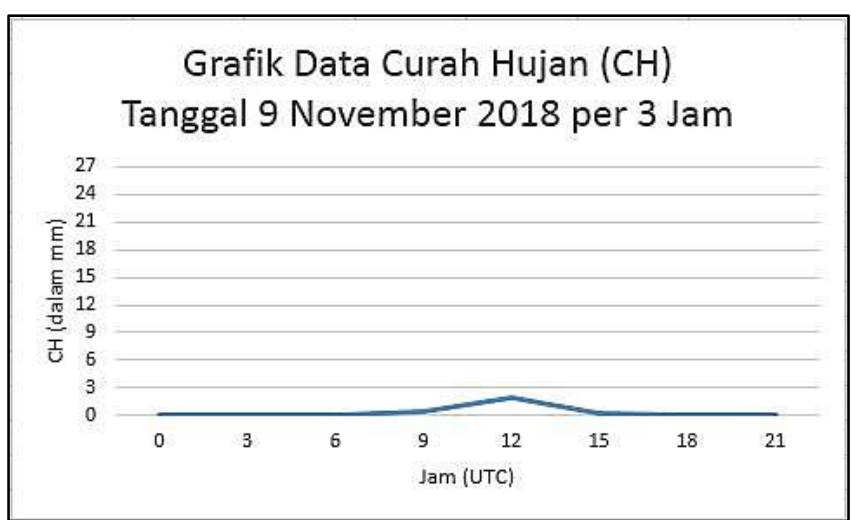

Gambar 3.1 Grafik Curah Hujan pada tanggal 9 November 2018 per 3 jam pengamatan.

Dari grafik 3.1 curah hujan diatas tercatat oleh Stasiun Meteorologi Citeko bahwa telah terjadi hujan antara pukul 06 hingga 09 UTC pada tanggal 9 November 2018. Puncak intensitas curah hujan tercatat pada pukul 12 UTC sebesar $2 \mathrm{~mm} / \mathrm{jam}$. Dan masih terjadi hujan hingga pukul 18 UTC dengan intensitas $0.3 \mathrm{~mm} / \mathrm{jam}$.

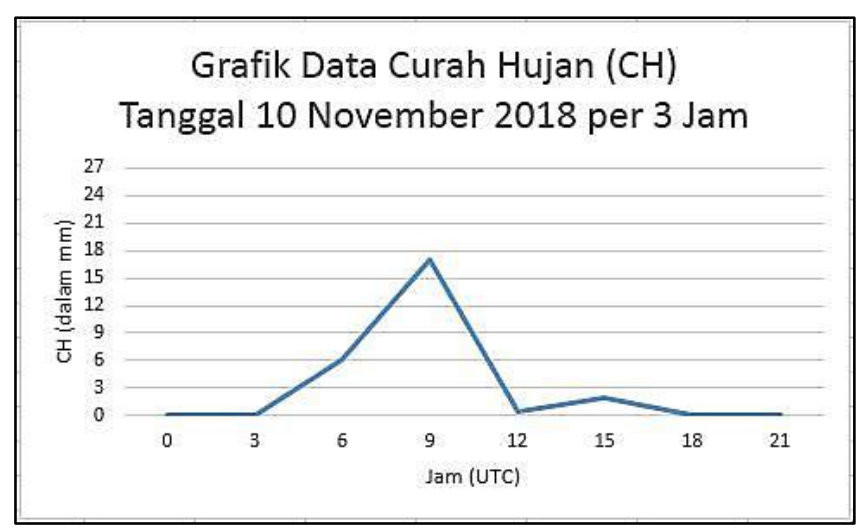

Gambar 3.2 Grafik Curah Hujan pada tanggal 10 November 2018 per 3 jam pengamatan.

Berdasarkan grafik 3.2 di atas, tercatat curah hujan mulai pukul 6 UTC (13.00 WIB) yang berarti telah terjadi hujan antara pukul 03 hingga 06 UTC (10.00 - 13.00 WIB). Puncak intensitas curah hujan terjadi pada pukul 09 UTC sebesar $17 \mathrm{~mm} / \mathrm{jam}$. Pada pukul $12 \mathrm{UTC}$ tidak terjadi hujan (hujan berhenti sesaat). Namun pada pukul 15 UTC tercatat telah terjadi hujan dengan intensitas $2 \mathrm{~mm} / \mathrm{jam}$. Total dalam 24 jam terdapat intensitas curah hujan sebanyak $25.5 \mathrm{~mm}$. 


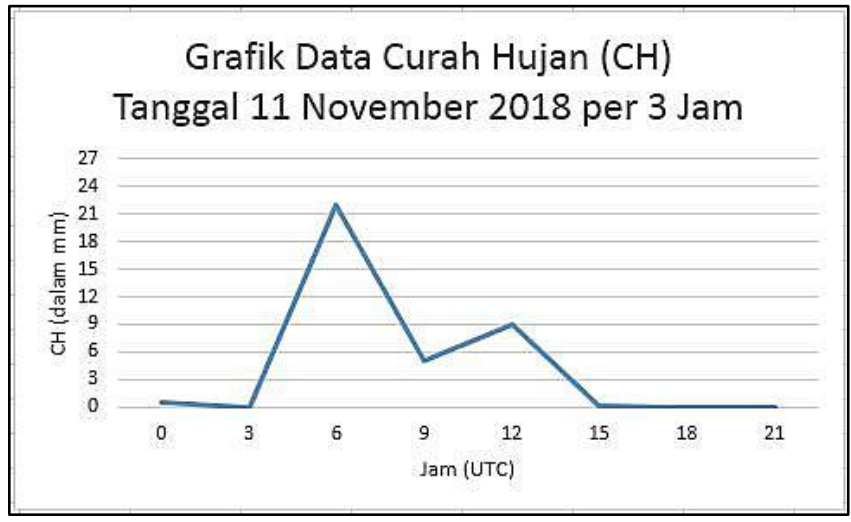

Gambar 3.3 Grafik Curah Hujan pada tanggal 11 November 2018 per 3 jam pengamatan.

Berdasarkan grafik 3.3 curah hujan di atas, telah terjadi hujan dengan intensitas 22 mm/jam. Di wilayah Bogor sejak pukul 03-15 UTC (10.00 - 22.00 WIB). Puncak maksimum intensitas curah hujan terjadi pada pukul 06 UTC sebesar $22 \mathrm{~mm} / \mathrm{jam}$. Curah hujan berkurang pada pukul 09 UTC (16.00 WIB) namun mengalami peningkatan pada pukul 12 UTC (19.00 WIB) yang artinya intensitas curah hujan mengalami fluktuasi. Total curah hujan pada tanggal 11 November 2018 adalah $36.6 \mathrm{~mm}$.

Berdasarkan grafik 3.1, grafik 3.2 dan grafik 3.3 dapat dilihat bahwa kejadian hujan di wilayah Bogor pada periode waktu tanggal 9, 10, dan 11 November 2018 rata-rata terjadi pada pukul 03-12 UTC. Dengan intensitas curah hujan yang mengalami fluktuasi dan semakin meningkat setiap harinya.

\subsection{Analisis Indeks Stabilitas Atmosfer pada Kejadian Hujan Lebat}

\subsubsection{Kejadian tanggal 9 November 2018}

Tabel 1. Kampung Lebak Soto

\begin{tabular}{cccc}
\hline Indeks & & JAM & $10: 30$ \\
\hline SSI & $08: 30$ & $09: 30$ & 2.2 \\
LI & 1.9 & 2 & -1.9 \\
SWEAT & -2.2 & -2 & 93 \\
CAPE & 127 & 107 & 381 \\
\hline
\end{tabular}

Berdasarkan data dari tabel 3.2.1 di atas, pada tanggal 9 November 2018 memiliki nilai SSI sebesar 1.9, 2 dan 2.2 yang artinya pada hari tersebut kondisi atmosfer menengah stabil. Untuk nilai LI memiliki rata rata sebesar -2.2, -2 dan -1.9 Nilai tersebut mengindikasikan bahwa kemungkinan terjadi petir dan kemungkinan kecil terjadi badai. Namun hasil berbeda pada nilai SWEAT dan CAPE. Nilai SWEAT sebesar 127, 107 dan 93 yang mengindikasikan bahwa potensi cuaca buruk sangat lemah. Dan Nilai CAPE sebesar 530, 437 dan 381 menunjukkan bahwa kondisi atmosfer cenderung stabil. 
Tabel 2. Kampung Padasuka

\begin{tabular}{cccc}
\hline Indeks & & JAM & \\
& $08: 30$ & $09: 30$ & $10: 30$ \\
\hline SSI & 1.7 & 1.9 & 2 \\
LI & -1.9 & -1.9 & $-1,9$ \\
SWEAT & 115 & 99 & 91 \\
CAPE & 419 & 394 & 378 \\
\hline
\end{tabular}

Berdasarkan data dari tabel 3.2.2 di atas, pada tanggal 9 November 2018 memiliki nilai SSI sebesar 1.7, 1.9 dan 2 yang artinya pada hari tersebut kondisi atmosfer menengah stabil. Untuk nilai LI memiliki rata rata sebesar -1.9. Nilai tersebut mengindikasikan bahwa kemungkinan terjadi petir dan kemungkinan kecil terjadi badai. Namun hasil berbeda pada nilai SWEAT dan CAPE. Nilai SWEAT sebesar 115, 99 dan 91 yang mengindikasikan bahwa potensi cuaca buruk sangat lemah. Dan Nilai CAPE sebesar 419, 394 dan 378 menunjukkan bahwa kondisi atmosfer cenderung stabil.

\subsubsection{Kejadian tanggal 10 November 2018}

Tabel 3. Kampung Lebak Soto

\begin{tabular}{cccc}
\hline Indeks & & JAM & $10: 30$ \\
\hline SSI & $08: 30$ & $09: 30$ & 1.3 \\
LI & 1.6 & 1.5 & -1.8 \\
SWEAT & -1.9 & -1.8 & 133 \\
CAPE & 122 & 127 & 340 \\
\hline
\end{tabular}

Berdasarkan data dari tabel 3.2.3 di atas, pada tanggal 10 November 2018 memiliki nilai SSI sebesar 1.6, 1.5 dan 1.3 yang artinya pada hari tersebut kondisi atmosfer menengah stabil. Untuk nilai LI memiliki rata rata sebesar -1.9, -1.8 dan -1.8 Nilai tersebut mengindikasikan bahwa kemungkinan terjadi petir dan kemungkinan kecil terjadi badai. Namun hasil berbeda pada nilai SWEAT dan CAPE. Nilai SWEAT sebesar 122, 127 dan 133 yang mengindikasikan bahwa potensi cuaca buruk sangat lemah. Dan Nilai CAPE sebesar 343, 332 dan 340 menunjukkan bahwa kondisi atmosfer cenderung stabil.

Tabel 4. Kampung Padasuka

\begin{tabular}{cccc}
\hline Indeks & & JAM & \\
& $08: 30$ & $09: 30$ & $10: 30$ \\
\hline SSI & 1.6 & 1.5 & 1.3 \\
LI & -1.9 & -1.9 & $-1,8$ \\
SWEAT & 122 & 127 & 132 \\
CAPE & 343 & 385 & 340 \\
\hline
\end{tabular}


Berdasarkan data dari tabel 3.2.4 di atas, pada tanggal 10 November 2018 memiliki nilai SSI sebesar 1.6, 1.5 dan 1.3 yang artinya pada hari tersebut kondisi atmosfer menengah stabil. Untuk nilai LI memiliki rata rata sebesar $-1.9,-1.9$ dan -1.8. Nilai tersebut mengindikasikan bahwa kemungkinan terjadi petir dan kemungkinan kecil terjadi badai. Namun hasil berbeda pada nilai SWEAT dan CAPE. Nilai SWEAT sebesar 122, 127 dan 132 yang mengindikasikan bahwa potensi cuaca buruk sangat lemah. Dan Nilai CAPE sebesar 343, 385 dan 340 menunjukkan bahwa kondisi atmosfer cenderung stabil.

\subsubsection{Kejadian tanggal 11 November 2018}

Tabel 5. Kampung Lebak Soto

\begin{tabular}{ccccc}
\hline Indeks & & & JAM & \\
& $05: 40$ & $06: 40$ & $07: 40$ & $08: 40$ \\
\hline SSI & 1.5 & 1.4 & 1.4 & 1.6 \\
LI & -2.2 & -2.4 & -2.3 & -2.3 \\
SWEAT & 122 & 157 & 160 & 162 \\
CAPE & 654 & 709 & 656 & 657
\end{tabular}

Berdasarkan data dari tabel 3.2.5 di atas, pada tanggal 11 November 2018 memiliki nilai SSI sebesar 1.5, 1.4, 1.4 dan 1.6 yang artinya pada hari tersebut kondisi atmosfer menengah stabil. Untuk nilai LI memiliki rata rata sebesar $-2.2,-2.4,-2.3$ dan -2.3 Nilai tersebut mengindikasikan bahwa kemungkinan terjadi petir dan kemungkinan kecil terjadi badai. Namun hasil berbeda pada nilai SWEAT dan CAPE. Nilai SWEAT sebesar 122, 157, 160 dan 162 yang mengindikasikan bahwa potensi cuaca buruk sangat lemah. Dan Nilai CAPE sebesar 654, 709, 656 dan 657 menunjukkan bahwa kondisi atmosfer cenderung stabil.

Tabel 6. Kampung Padasuka

\begin{tabular}{ccccc}
\hline Indeks & & \multicolumn{2}{c}{ JAM } & \\
& $05: 40$ & $06: 40$ & $07: 40$ & $08: 40$ \\
\hline SSI & 1.5 & 1.4 & 1.4 & 1.6 \\
LI & -2.2 & -2.3 & -2.3 & -2.2 \\
SWEAT & 131 & 157 & 158 & 162 \\
CAPE & 654 & 662 & 628 & 583 \\
\hline
\end{tabular}

Berdasarkan data dari tabel 3.2.6 di atas, pada tanggal 11 November 2018 memiliki nilai SSI sebesar 1.5, 1.4, 1.4 dan 1.6 yang artinya pada hari tersebut kondisi atmosfer menengah stabil. Untuk nilai LI memiliki rata rata sebesar -2.2 dan -2.3. Nilai tersebut mengindikasikan bahwa kemungkinan terjadi petir dan kemungkinan kecil terjadi badai. Namun hasil berbeda pada nilai SWEAT dan CAPE. Nilai SWEAT sebesar 131, 157, 158 dan 162 yang mengindikasikan bahwa potensi cuaca buruk sangat lemah. Dan Nilai CAPE sebesar 654, 662, 628 dan 583 menunjukkan bahwa kondisi atmosfer cenderung stabil. 


\subsection{Analisis Tutupan Awan dari Citra Satelit}

\subsubsection{Kejadian tanggal 9 November 2018}

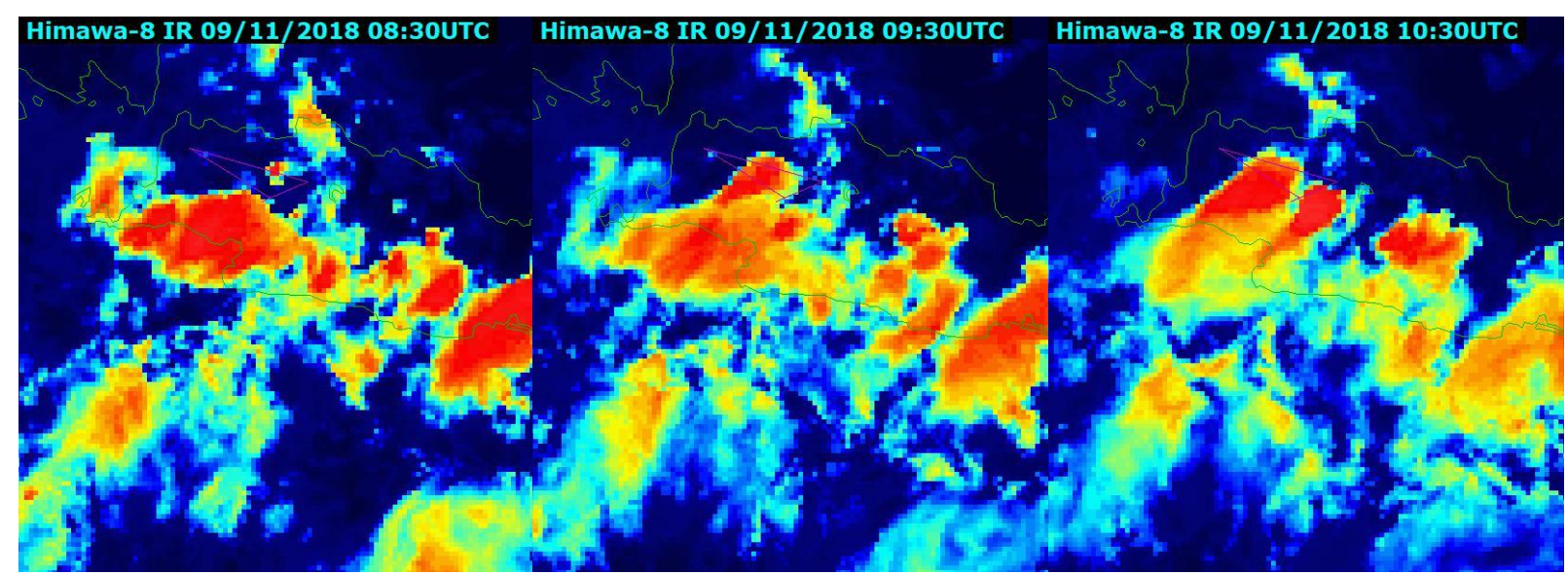

Gambar 3.4 Gambar tutupan awan pada tanggal 9 November 2018 jam 08.30 - 10.30 UTC.

Berdasarkan gambar 3.4 diatas, tampak wilayah Bogor tertutup oleh awan konvektif yang cukup tebal sehingga menyebabkan intensitas hujan ringan hingga sedang pada pukul 08.30 UTC sampai 10.30 UTC.

\subsubsection{Kejadian tanggal 10 November 2018}

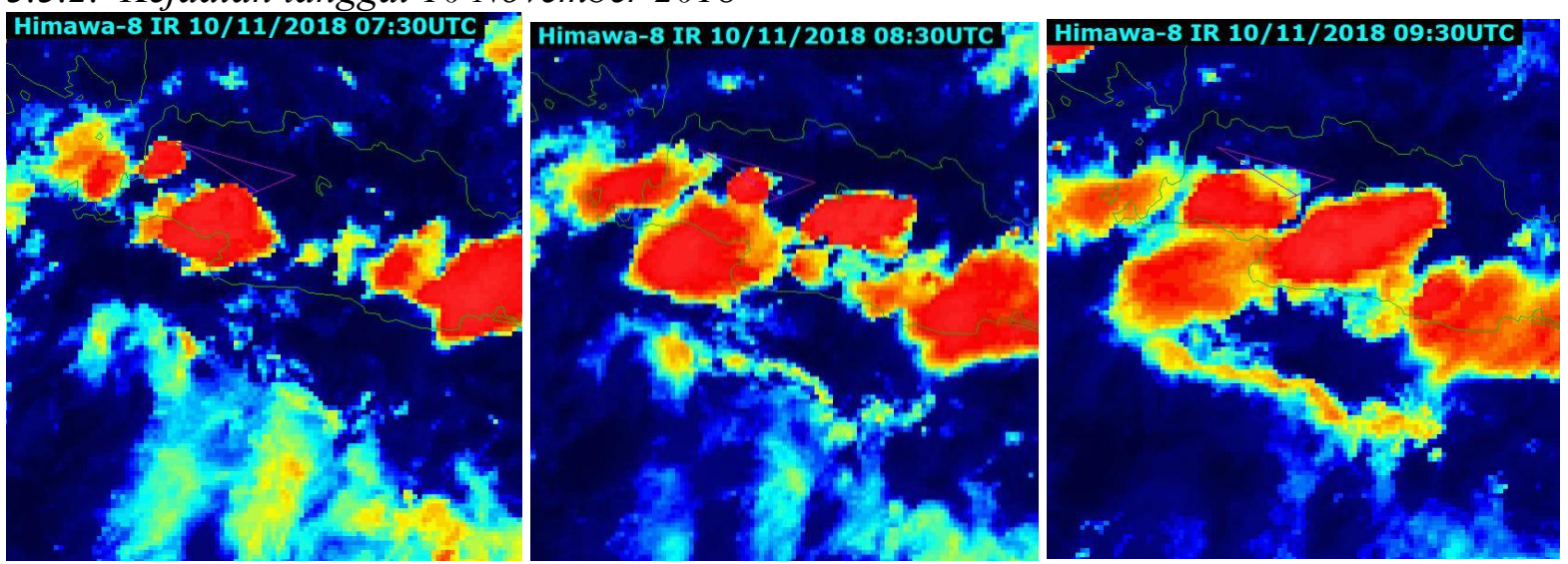

Gambar 3.5 Gambar tutupan awan pada tanggal 10 November 2018 jam 07.30 - 09.30 UTC.

Berdasarkan gambar 3.5 diatas, tampak wilayah Bogor tertutup oleh awan konvektif yang cukup tebal sehingga menyebabkan intensitas hujan ringan hingga sedang pada pukul 07.30 UTC sampai 09.30 UTC. Intensitas hujan mencapai $25.5 \mathrm{~mm} / \mathrm{hari}$. 


\subsubsection{Kejadian tanggal 11 November 2018}

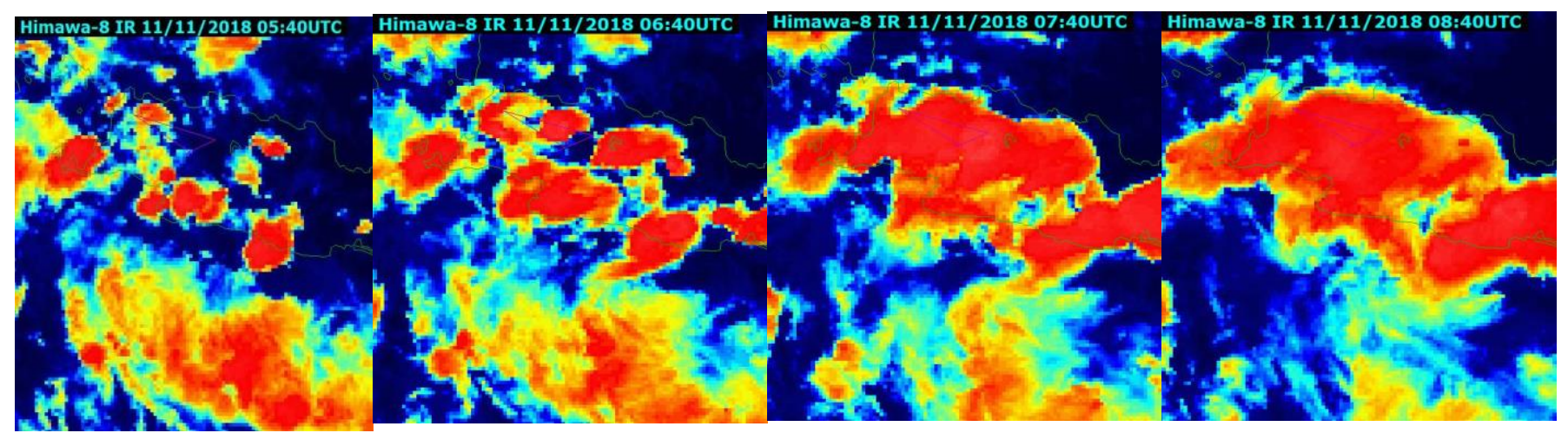

Gambar 3.6 Gambar tutupan awan pada tanggal 11 November 2018 jam 05.40 - 08.40 UTC.

Berdasarkan gambar 3.6 diatas, tampak wilayah Bogor tertutup oleh awan konvektif yang cukup tebal sehingga menyebabkan intensitas hujan ringan hingga sedang pada pukul 05.40 UTC sampai 08.40 UTC. Intensitas hujan mencapai $22 \mathrm{~mm} / 3$ jam pengamatan hingga 36.6 mm pada tanggal 11 November 2018.

\section{KESIMPULAN}

Berdasarkan hasil pembahasan dapat ditarik kesimpulan melalui grafik intensitas curah hujan dapat dilihat bahwa kejadian hujan di Bogor pada periode waktu tanggal 9, 10, dan 11 November 2018 rata-rata terjadi pada pukul 3-12 UTC dengan tendensi curah hujan yang semakin meningkat dari setiap harinya dan berbanding lurus dengan variasi indeks stabilitas udara pada hari-hari tersebut.

Kemudian dari citra satelit dapat dilihat bahwa cakupan awan konvekif selalu menutupi wilayah Bogor selama periode tanggal 9-11 November 2018

\section{DAFTAR PUSTAKA}

Nurrohman, F., Bayong, T. (2016). Kajian Indeks Stabilitas Atmosfer Terhadap Kejadian Hujan Lebat di Wilayah Makassar (Studi Kasus Bulan Desember 2013-2014). Jurnal Meteorologi Klimatologi dan Geofisika 3(2). Puslitbang BMKG. Jakarta.

Budiarti, M., M. Muslim, dan Y. Ilhamsyah. 2012. Studi Indeks Stabilitas Udara Terhadap Prediksi Kejadian Badai Guntur di Wilayah Stamet Cengkareng Banten. Jurnal Meteorologi dan Geofisika 13(2). Puslitbang BMKG. Jakarta.

Manurung, M.R 2012. Prediktabilitas Cuaca Jangka Pendek Ditinjau dari Indeks Stabilitas di Jakarta. Jurnal Teknologi Mineral 19(3). ITB. Bandung.

Nurlatifah, S. 2012. Pemanfaatan Data Satelit Cuaca MTSAT Untuk Estimasi Curah Hujan di Stasiun Meteorologi Tegal dan Stasiun Meteorologi Citeko. Tugas Akhir. AMG. Jakarta.

Nuryanto, D.E. 2011. Aktifitas Konvektif di Atas Benua Maritim Indonesia dan Keterkaitannya dengan Variabilitas Iklim Regional dan Lokal. Institut Teknologi Bandung. Bandung.

Peppler, R.A., 1988, A Review of Static Stability Indices and Related Thermodynamic Parameters. Illinois Department of Energy and Natural Resources, Illinois. 
Zakir, A., W. Sulistya, dan M.K. Khotimah. 2010. Perspektif Operasional Cuaca Tropis. Puslitbang BMKG. Jakarta. 